\title{
EARLY POSTOPERATIVE MEASUREMENT OF CALCIUM AND PARATHRMONE LEVELS AS PREDICTORS OF EARLY PARATHYROID INSUFFICIENCY AFTER TOTAL THYROIDECTOMY
}

\author{
Ahmed Samir Awad, Mohamed Hassan, Mohamed Selim Aboud, Ahmed Raafat Abd-Elftaah and \\ Nermin Raafat" \\ General Surgery \& Biochemistry* departments, Faculty of Medicine, Zagazig University.
} \begin{abstract}
Background: Declines in serum calcium or intact parathyroid hormone (iPTH) levels after surgery have been suggested as being reliable predictors of postoperative hypocalcemia. Although measurements of serum calcium or iPTH allow the identification of patients who have no risk of hypocalcemia after total thyroidectomy, it is not always easy to predict which patients can be discharged early from the hospital or to identify those requiring close monitoring of serum calcium levels or those that should receive calcium and vitamin D supplements. Aim of the work To evaluate early postoperative parathyroid insufficiency following total thyroidectomy by estimating parathyroid hormone and calcium level in the early postoperative period, and whether we can rely on to start $\mathrm{Ca}$ supplement or not. Patients and methods: This study was done in General Surgery department, Zagazig University on 50 patients; 10 males (20\%)) 40 females $(80 \%)$ who underwent total thyroidectomy. Serum total Calcium and Parathormone levels were evaluated in all patients $6 \mathrm{~h}$ and $24 \mathrm{~h}$ in early postoperative period. Results: Our results showed highly significant VALUE OF relative decline of serum calcium and parathyroid hormone $6 \mathrm{~h}$ and $24 \mathrm{~h}$ after total thyroidectomy. The results showed also highly significant positive correlation between serum calcium and parathyroid hormone both preoperative and postoperative and highly significant positive correlation between relative decline in serum calcium and relative decline of serum parathyroid hormone at both $6 \mathrm{~h}$ and $24 \mathrm{~h}$ after total thyroidectomy IN HYPO CALCEMIC PATIENTS. There was no significant relationship between hypocalcemia and any of demographic, clinical, ultrasonographic and pathological data. There is significant relationship between both relative decline of serum calcium and relative decline parathyroid hormone and postoperative hypocalcemia. Conclusion: Relative decline of parathyroid hormone $6 \mathrm{~h}$ and $24 \mathrm{~h}$ after total thyroidecomy is a good predictor of postoperative hypocalcemia and is reliable for allowing safety discharge of patients $24 \mathrm{~h}$ after total thyroidectomy.

Key words: Total thyroidectomy, Calcium, Parathyroid hormone
\end{abstract}

\section{INTRODUCTION}

$\mathbf{P}$ ostoperative hypocalcemia is observed in up to one third of total or completion thryoidectomy patients and is the most common complication (I). Hypocalcemia after total thyroidectomy is usually transient, and the incidence of permanent hypoparathyroidism is $3 \%$ or less according to the experience of most of the surgical units. Despite being self-limiting in most patients, symptomatic hypocalcemia is of particular concern because of a delay in its manifestation and the consequent need for prolonged patient hospitalization or readmission (2).

Several authors have attempted to identify risk factors in the development of hypocalcemia. Declines in serum calcium or intact parathyroid hormone (iPTH) levels after surgery have been suggested as being reliable predictors of postoperative hypocalcemia. Although measurements of serum calcium or iPTH allow the identification of patients who have no risk of hypocalcemia after total thyroidectomy, it is not always easy to predict which patients can be discharged early from the hospital or to identify those requiring close monitoring of serum calcium levels or those that should receive calcium and vitamin D supplements (3).

Routine oral calcium and vitamin D supplements have been proposed to prevent the development of symptomatic hypocalcemia and to increase the likelihood of early hospital discharge after bilateral surgical treatment of the thyroid gland or exploration of the parathyroid glands. Because symptomatic hypocalcemia usually develops as late as 24 hours to several days after surgery, postoperative treatment with oral calcium and vitamin $\mathrm{D}$ may be a useful approach for avoiding the risk of postoperative hypocalcemic crisis ((2)).

\section{AIM OF THE WORK}

To evaluate early postoperative parathyroid insufficiency following total thyroidectomy by calculating parathyroid hormone and calcium level in the early postoperative period, and whether we can relay on to start $\mathrm{Ca}$ supplement or not.

\section{PATIENTS AND METHODS}

This is a prospective study of fifty patients who underwent total thyroidectomy. This number included the patients who under went follow up in early post operative period for 24 hours.

All cases were operated upon in the department of General Surgery, Zagazig University Hospitals during the period from June 2009 to June 2013. 


\section{METHODS}

\section{$\triangle$ Pre operative measures:}

Each patient was assessed clinically in the form of clinical history, clinical examination, and laboratory investigations.

All patients subjected to the assessment of vocal cord mobility by indirect laryngoscopy.

\section{1) Clinical history and examination:}

A detailed history including personal data, presenting symptoms as thyroid swelling, lymph nodes, toxic symptoms, pain, pressure symptoms and, primary or re-surgery, medication for hyper or hypothyroidism.

Full clinical examination including general assessment for signs of hyper or hypothyroidism and fitness for surgery, and local examination of the thyroid gland and neck region for the swelling characters, presence or absence of lymph nodes, fixation to the trachea and to adjacent structures, tracheal shift, retro sternal extension, scar of previous operations for thyroid or central neck.

2) Laboratory and radiological investigations:

- Routine preoperative investigations for all patients as in any major surgery, as CBC, KFT, electrolytes, chest x-ray.

- Thyroid, and neck U/S. done for all cases.

- Thyroid scan (optional) done when indicated in toxic and malignant cases.

- Preoperative thyroid function test (TFT) T4 $[$ Normal range $=12.0-22.0 \mathrm{P} \mathrm{mol} / \mathrm{L}], \quad \mathrm{TSH}$ [normal range $=0.270-4.20 \mathrm{~m} \mathrm{IU} / \mathrm{L}]$.

- Pre operative parathyroid function tests in the form of:

Serum calcium level. [Normal range $=2.22-2.6 \mathrm{~m}$ $\mathrm{mol} / \mathrm{L}-(9-10.5 \mathrm{mg} / \mathrm{dL})]$

3) Fine needle aspiration cytology (FNAC). Done for all patients.

\section{Operative technique:}

All operations were done under general anesthesia in supine neck extension position and all cases were operated for total thyroidectomy.

\section{$\checkmark$ Postoperative and follow up:}

Clinical evaluation for the presence of clinical symptoms or signs of hypocalcaemia (tetany) by doing Chvostek's or Trousseau's tests every 4 hours.

Post operative thyroid function done once for all patients in the form of TSH, T3 and T4, within the $1^{\text {st }}$ week of surgery.

\section{RESULTS}

Table (1): Demographic data of patients.

\begin{tabular}{|c|c|}
\hline Parameter & $\mathrm{N}=\mathbf{5 0}$ \\
\hline Age (years) & \\
\hline $\bar{X} \pm \mathrm{SD}$ & $40.1 \pm 11.54$ \\
\hline Range & $22-70$ \\
\hline $\operatorname{Gender}(N, \%)$ & $\mathbf{N}$ \\
\hline
\end{tabular}

\begin{tabular}{llc}
\hline Male & 10 & $20 \%$ \\
\hline Female & 40 & $80 \%$ \\
\hline
\end{tabular}

This table shows that the incidence is higher in female 40 patients $(80 \%)$ and lower in male 10 patients $(20 \%)$.

Table (2): Clinical presentation of patients

\begin{tabular}{lcc}
\hline \multicolumn{1}{c}{ Clinical presentations } & N & $\%$ \\
\hline Swelling & 41 & 82.0 \\
\hline Pressure & 14 & 28.0 \\
\hline Toxic symptoms & 14 & 28.0 \\
\hline Pain & 6 & 12.0 \\
\hline Lymph node enlargement & 8 & 16.0 \\
\hline
\end{tabular}

This table shows that thyroid swelling was the commonest clinical presentation in our patients followed by pressure and toxic symptoms and lastly pain and lymph node enlargement.

Table (3): Ultrasound findings of patients.

\begin{tabular}{lcc}
\hline & N & $\%$ \\
\hline Solitary cystic mass & 2 & 4.0 \\
\hline Solitary solid mass & 14 & 28.0 \\
\hline Multi nodular goiter & 34 & 68.0 \\
\hline Lymph node enlargement & 8 & 16.0 \\
\hline
\end{tabular}

This table shows that the commonest finding by neck ultrasound is multi nodular goiter followed by solitary solid mass and lastly solitary cystic mass and lymph node enlargement was found in $16 \%$ of patients.

Table (4): Fine needle aspiration cytology of thyroid swelling in our patients.

\begin{tabular}{lcc}
\hline & N & \% \\
\hline Malignant & 4 & 8.0 \\
\hline Benign & 45 & 90.0 \\
\hline Susp. & 1 & 2.0 \\
\hline
\end{tabular}

This table shows that most cases $45(90 \%)$ was benign by FNAC followed by malignant in $4(8 \%)$ and suspicious in one case $(2 \%)$ of all studied patients.

Table (5): Preoperative and early postoperative serum Calcium levels.

\begin{tabular}{lc}
\hline & $\bar{X} \pm$ SD (Range) \\
\hline Preoperative & $9.1 \pm 0.65(7.8-10.5)$ \\
\hline 6 h postoperative & $8.5 \pm 1.4(4.8-10.4)$ \\
\hline 24 h postoperative & $8.6 \pm 1.3(5.4-10.4)$ \\
\hline
\end{tabular}

Table (6): Preoperative and postoperative serum parathyroid hormone levels.

\begin{tabular}{lc}
\hline & $\bar{X} \pm$ SD (Range) \\
\hline Preoperative & $29.1 \pm 10.1(12.5-49.8)$ \\
\hline 6 h postoperative & $25.7 \pm 13.2(4.4-50.0)$ \\
\hline 24 h postoperative & $25.6 \pm 13.2(4.3-50.1)$ \\
\hline
\end{tabular}


Table (7): Relative decline of serum Calcium after total thyroidectomy in all studied patients

\begin{tabular}{ccc}
$\begin{array}{c}\text { Mean \% } \\
\text { of change }\end{array}$ & Paired & P value \\
\hline-6.05 & 2.98 & $0.004^{* *}$ \\
\hline$-5.7 \%$ & 3.01 & $0.004^{* *}$ \\
\hline
\end{tabular}

This table shows that there is highly significant relative decline of serum calcium $6 \mathrm{~h}$ and $24 \mathrm{~h}$ after total thyroidectomy.

Table (8): Relative decline of serum parathyroid hormone after total thyroidectomy in all studied patients

\begin{tabular}{lccl}
\hline & $\begin{array}{c}\text { Mean \% } \\
\text { of change }\end{array}$ & Paired & P value \\
\hline $\mathbf{6} \boldsymbol{h}$ & -14.4 & 3.62 & $<0.001^{* *}$ \\
\hline $\mathbf{2 4} \boldsymbol{h}$ & $-14.5 \%$ & 3.625 & $<0.001^{* *}$ \\
\hline
\end{tabular}

This table shows that there is highly significant relative decline of serum parathyroid hormone $6 \mathrm{~h}$ and $24 \mathrm{~h}$ after total thyroidectomy.

Table (9): Prevalence of hypocalcemia in our studied patients

\begin{tabular}{lcc}
\hline Total & $\mathbf{N}=\mathbf{5 0}$ & $\mathbf{1 0 0 \%}$ \\
\hline Hypocalcemia & 8 & $16 \%$ \\
\hline Manifest tetany & 5 & $10 \%$ \\
\hline Latent tetany & 3 & $6.0 \%$ \\
\hline
\end{tabular}

Hypocalcemia was founded in $8(16 \%)$ of our patients after total thyroidectomy it was manifested in $5(10 \%)$ patients and asymptomatic in $3(6 \%)$ patients.

Table (10): Relative decline of serum calcium in patients with hypocalcemia after total thyroidectomy.

\begin{tabular}{lc}
\hline & Mean \% of change \\
\hline $\mathbf{6 h}$ & $-33.8 \%$ \\
\hline $\mathbf{2 4 h}$ & -30.0 \\
\hline
\end{tabular}

This table shows that the mean change of serum calcium after total thyroidectomy was $-33.8 \%$ and $-30.0 \%$ after $6 \mathrm{~h}$ and $24 \mathrm{~h}$ respectively.

Table (11): Relative decline of serum parathyroid hormone in patients with hypocalcemia after total thyroidectomy.

\begin{tabular}{lc}
\hline & Mean \% of change \\
\hline $\mathbf{6 h}$ & $-66.1 \%$ \\
\hline $\mathbf{2 4 h}$ & -68.24 \\
\hline
\end{tabular}

This table shows that the mean change of serum parathyroid after total thyroidectomy was $-66.1 \%$ and $-68.24 \%$ after $6 \mathrm{~h}$ and $24 \mathrm{~h}$ respectively.

Table (12): Correlation between serum Calcium and parathyroid hormone in all studied patients

\begin{tabular}{lccc}
\hline & r & P & Significant \\
\hline Pre & 0.39 & $<0.001$ & Highly significant \\
\hline $\mathbf{6} \boldsymbol{h}$ & 0.72 & $<0.001$ & Highly significant \\
\hline $\mathbf{2 4} \boldsymbol{h}$ & 0.73 & $<0.001$ & Highly significant \\
\hline
\end{tabular}

This table shows that there is highly significant positive correlation between serum calcium and parathyroid hormone both preoperative and postoperative.

Table (13): Correlation between relative decline in serumCalcium and serum parathyroid hormone in all studied patients

\begin{tabular}{lccc}
\hline & $\mathbf{r}$ & $\mathbf{P}$ & Significant \\
\hline $\mathbf{6} \boldsymbol{h}$ & 0.92 & $<0.001$ & Highly significant \\
\hline $\mathbf{2 4} \boldsymbol{h}$ & 0.92 & $<0.001$ & Highly significant \\
\hline
\end{tabular}

This table shows that there is highly significant positive correlation between relative decline in serum calcium and relative decline of serum parathyroid hormone at both $6 \mathrm{~h}$ and $24 \mathrm{~h}$ after total thyroidectomy.

Table (14): Comparison between patients with and without postoperative hypocaelcemia as regards to demographic, clinical presentation, ultrasonographic findings and pathological findings.

\begin{tabular}{|c|c|}
\hline$\underset{42}{\text { Normal }} \quad \mathrm{N}=$ & $\begin{array}{r}\text { Hypocalcima } \\
=8\end{array}$ \\
\hline
\end{tabular}

\begin{tabular}{|c|c|c|c|c|c|}
\hline \multicolumn{6}{|l|}{ Age (years) } \\
\hline \multirow{2}{*}{$\bar{X}_{ \pm \mathrm{SD}}$} & \multicolumn{2}{|c|}{$39.1 \pm 11.7$} & \multicolumn{2}{|c|}{$45.8 \pm 8.9$} & \multirow[t]{2}{*}{0.15} \\
\hline & $\mathbf{N}$ & $\%$ & $\mathbf{N}$ & $\%$ & \\
\hline \multicolumn{6}{|l|}{ Gender } \\
\hline Male & 10 & 23.8 & 0 & 0.0 & 0.31 \\
\hline Female & 32 & 16.20 & 8 & 100.0 & \\
\hline \multicolumn{6}{|l|}{ Clinical presentation } \\
\hline Swelling & 34 & 81.0 & 7 & 87.5 & 0.95 \\
\hline Pressure symptoms & 12 & 28.6 & 2 & 25.0 & 0.82 \\
\hline Toxic symptoms & 14 & 33.3 & 0 & 0.0 & 0.13 \\
\hline Lymph node enlargement & 5 & 11.9 & 1 & 12.5 & 1.0 \\
\hline
\end{tabular}




\begin{tabular}{lccccc}
\hline Pain & 6 & 14.3 & 2 & 25.0 & 0.59 \\
\hline Ultrasound findings & & & & & \\
\hline Cystic & 2 & 4.8 & 0 & 0.0 & 0.72 \\
\hline Solid & 14 & 33.3 & 0 & 0.0 & 0.09 \\
\hline Multi nodular goiter & 26 & 61.9 & 8 & $100.0^{*}$ & $0.04^{*}$ \\
\hline Lymph node enlargement & 7 & 16.7 & 1 & 12.5 & 1.0 \\
\hline Pathology & & & & & \\
\hline Malignant & 2 & 4.8 & 1 & 12.5 & \\
\hline Benign & 39 & 92.9 & 6 & 75.0 & \\
\hline Susp. & 1 & 2.4 & 0 & 0.0 & \\
\hline
\end{tabular}

A part from multinodular goitre which has a significant relationship to postoperative hypocalcemia, there was no significant relationship between hypocalcemia and any of demographic, clinical, ultrasonographic and pathological data.

Table (15): Relative decline of serum calcium and parathyroid hormone in patients with and without hypocalcemia.

\begin{tabular}{lccc}
\hline & Normal & Hypocalcemia & P \\
\hline Relative decline in calcium & & & $<0.001$ \\
\hline $6 \mathrm{~h}$ & 0.81 & 33.6 & $<0.001$ \\
\hline $24 \mathrm{~h}$ & 1.1 & 29.9 & $<0.001$ \\
\hline Relative decline in parathyroid hormone & & & $<0.001$ \\
\hline $6 \mathrm{~h}$ & 4.6 & 66.1 & 68.2 \\
\hline $24 \mathrm{~h}$ & 4.3 & 6 & \\
\hline
\end{tabular}

There is significant relationship between both relative decline of serum calcium and relative decline parathyroid hormone and postoperative hypocalcemia.

\section{DISCUSSION}

The two primary potential complications that must be considered in performing thyroid surgery are RLN injury and hypoparathyroidism. Both can be further stratified into temporary and permanent categories (4).

Postoperative hypocalcemia is observed in up to one third of total or completion thryoidectomy patients and is the most common complication (1). Hypocalcemia after total thyroidectomy is usually transient, and the incidence of permanent hypoparathyroidism is $3 \%$ or less according to the experience of most of surgeons. Despite being self-limiting in most patients, symptomatic hypocalcemia is of particular concern because of a delay in its manifestation and the consequent need for prolonged patient hospitalization or readmission (2).

There are many controversies and many differences in the design of studies on hypocalcemia and PTH after thyroidectomy. Some series have used rapid determination (intraoperative) of $\mathrm{PTH}$, and others have used intact PTH determination (5).

Several authors have attempted to identify risk factors in the development of hypocalcemia. Declines in serum calcium or intact parathyroid hormone (iPTH) levels after surgery have been suggested as being reliable predictors of postoperative hypocalcemia. Although measurements of serum calcium or iPTH allow the identification of patients who have no risk of hypocalcemia after total thyroidectomy, it is not always easy to predict which patients can be discharged early from the hospital or to identify those requiring close monitoring of serum calcium levels or those that should receive calcium and vitamin D supplements (3).

In the modern climate of increasing cost awareness, thyroid surgery has been considered for a 1 day- surgery regime with limiting factors for early discharge being postoperative bleeding (1-2\%), bilateral recurrent laryngeal nerve palsy and symptomatic hypocalcemia (6.7).

In our study we aimed to evaluate early postoperative parathyroid insufficiency following total thyroidectomy by calculating parathyroid hormone and calcium level in the early postoperative period, and whether we can relay on to start Ca supplement or not.

In this study, overall incidence of hypocalcemia was $16 \%$. Hypocalcemia was manifest in $10 \%$ and asymptomatic in $6 \%$.

This finding is in agreement with most other authors who reported incidence between 20-30\% with symptoms ranging from numbness to tetany (Del Rio et al., 2011).

(8), reported higher figures than our study (overall 
incidence $28.5 \%$, symptomatic in $14.6 \%$ and asymptomatic in $13.9 \%$ ). The difference in number of patients between their study and our study (137 patients compared to 50 patients may be responsible for this difference.

Apart from multi nodular goitre which had a significant relationship to postoperative hypocalcemia after total thryoidectomy, there was no significant relationship between postoperative hypocalcemia and any of demographic, clinical, ultrasonographic and pathological data.

Our results are matched with those reported by $(8)$, who found that there was no significant difference between hypocalcemia and normocalcemic patients according o sex, age, type of pathology and neck dissection.

This finding is accepted as surgery for multi nodular goitre carries the two risk factors that cause hylpocalcemia (ischaemia of parathyroid gland or surgical removal).

Our results showed that the mean change of serum calcium after total thyroidectomy was-33.8\% and $-30.0 \%$ after $6 \mathrm{~h}$ and $24 \mathrm{~h}$ respectively and the mean change of serum parathyroid hormone after total thyroidectomy was $-66.1 \%$ and $-68.24 \%$ after $6 \mathrm{~h}$ and $24 \mathrm{~h}$ respectively (Table 10,11).

In our study there was highly significant correlation between relative decline in serum calcium and relative decline of serum parathyroid hormone at both $6 \mathrm{~h}$ and $24 \mathrm{~h}$ after total thyroidectomy (Table 7,8).

This finding is supported by the findings of many authors. (8), reported that patients who developed postoperative hypocalcemia had a significantly lower parathyroid hormone after 4 hours of total thyroidectomy and a significantly greater parathyroid hormone decline and they noted that the threshold enabling prediction of hypocalcemia were $19.4 \mathrm{mg} / \mathrm{L}$ for parathyroid hormone after $4 \mathrm{~h}$ of total thyroidectomy and $68.5 \%$ for relative parathyroid hormone decline.

In this study we used estimation of serum calcium and parathyroid hormone $6,24 \mathrm{~h}$ postoperative depending upon the fact that hypocalcemia may occur early postoperative and also may be delayed up to $24 \mathrm{~h}$ this is supported by findings of may authors $(9,10)$.

In this study, there was a significant correlation between serum calcium and parathyroid hormone in all patients (Table 12). This is explained as the normal physiology. A findings that supports the choice of parathyroid hormone as a predictor of postoperative hypocalcemia this findings is supported by many other studies but these studies vary widely in terms of trial type methodology, measurement technique, timing and threshold maintained $(11,12)$.
(13), suggested that quick parathyroid hormone assay might have a value concerning the studies which investigated the optimal timing of the measurement, they didn't show any difference between measurements taken at 10 minutes, 1,4,6, or 24 hours. Only (14) found greater precision with measurements taken at 4 and 6 hours.

On the other hand $(\mathbf{1 5 , 1 6 )}$, concluded that parathyroid hormone serum level didn't accurately predict postoperative hypocalcemia. In an Australian review of 458 patients in 2007, 7\% of patients with a normal parathyroid hormone level developed hypocalcemia.

Depending on the threshold maintained, the single measurement of parathyroid hormone conflicts with a lack of sensitivity or specificity. To resolve this threshold problem. We studied the relative parathyroid hormone decline between its preoperative and postoperative values. We found highly significant correlation between relative decline in serum calcium and parathyroid hormone (table 13).

(17) in analysis of observational studies relevant to PTH decline, investigators found that with a threshold of parathyroid hormone decline (after $6 \mathrm{~h})$ of $65 \%$ sensitivity and specificity values were respectively $46.4 \%$ and $91.4 \%$. With a threshold decline of $70 \%$ sensitivity and specificity were 93.3\% and $88 \%$ respectively.

This is supported by the work of many authors, and the threshold of parathyroid hormone decline was found in different publications vary from $62.5-75.7 \%(18,11)$.

\section{REFERENCES}

1. Reeve $\mathrm{T}$ and Thompson NW (2000): complications of thyroid surgery: how to avoid them, how to mange them, and observations on their possible effect on the whole patient. World J Surg; 24: 971-975.

2. Jong-Lyel R and Chen E (2006): Routine oral calcium and vitamin D supplements for prevention of hypocalcemia after total thyroidectomy. Available online 27 October.

3. Lindblom P, Westerdahl $\mathbf{J}$ and Bergenfelz A (2002): Low parathyroid hormone levels after thyroid surgery: A feasible predictor of hypocalcemia. Surgery; 131: 515-20.

4. White WM, Randolph GW, Hartnick CJ et al. (2009): Recurrent laryngeal nerve monitoring during thyroidectomy and related cervical procedures in the pediatric population. Arch Otolaryngol Head Neck Surg; 135: 88-94.

5. Laura Del Rio Alejandro Castro Ricardobemaldez Et Al 2011 Parathyroidhormone As A Predictor Of Post Thyroidectomy Hypocalcemia Acta Otorrinolaringologica Espanola Volume62 Issue4 2011 Pages265\27

6. Gac EP, Cabane TP, Amat VJ et al. (2007): Incidence of hypocalcemia after total 
thyroidectomy. Rev Med Chil; 135 (1): 26-30.

7. Leahu A, Carroni V and Biliotti G (2009): Calcium level, a predictive factor of hypocalocemia following total thyroidectomy. Jurnalul de Chirurgie, Lasi; 5 (2): 1589-9341.

8. Lecerf P, Orry D, Perrodeau E et al. (2012): Parathyroid hormone decline 4 hours after total thyroidectomy accurately predicts hypocalcemia. Surgery, 152 (5): 863-868.

9. Noordzij JP, Lee SL, Bernet VJ, Payne RJ et al. (2007): Early prediction of hypocalcemia after thyroidectomy using parathyroid hormone: an analysis of pooled individual patient data from nine observational studies. J Am Coll Surg. Dec;205(6):748-54. Epub 2007 Sep 18.

10. Jumaily JS, Noordzij JP, Dukas AG et al. (2010): Prediction of hypocalcemia after using 1-to6 hours postoperative parathyroid hormone and calcium levels: an analysis of pooled individual patient data from 3 observational studies. Head Neck, 32: 427-434.

11. Grodski S and Serpell (2008): Evidence for the role perioperaitve PTH measurement after total thryoidectomy as a predictor of hypocalcemia. World J Sur; 32: 1367-73.

12. Toniato A, Boschin MI, Piotto A et al. (2008): Thyroidectomy and parathyroid hormone: tracing hypocalcemia prone patients. The American journal of surgery, 196: 285-288.

13. Lo CY, Luk JM and Tam SC (2002): Applicability of intraoperative parathyroid hormone assay during thyroidectomy. Ann Surg; 236: 564-569.

14. Lombardi PC, Raffaelli M, Princi P et al. (2004): Early prediction of post thyroidectomy hypocalcemia by one single iPTH measurement. Surgery; 136: 1236-41.

15. DelRio P, Arcuri FM, Ferreri G et al. (2005): The utility of serum PTH assessment 24 hours after total thyroidectomy. Otolaryngal Head Neck Surg; 132; 584-86.

16. Ghaheri BA, Liebler SL, Andersen PE et al. (2006): Perioperative parathyroid hormone levels in thyroid surgery. Laryngoscope, 116: 518-521.

17. Noordzij PJ, Lee LS, Bernet JV et al. (2007): Early prediction of hypocalcemia after thyroidectomy using parathyroid hormone: an analysis of pooled individual patient data from nine observational studies. J Am Coll Surg; 205: 748-724.

18. McLeod IK, Arciero C, Noordzij JP et al. (2006): The use of rapid parathyroid hormone assay in predicting postoperative hypocalcemia after total or completion thyroidectomy. Thyroid, 16: 259 265. 